\title{
Control of nanostructures in PVA, PVA/chitosan blends and PCL through electrospinning
}

\author{
U S SAJEEV, K ANOOP ANAND, DEEPTHY MENON and SHANTI NAIR* \\ Amrita Centre for Nanosciences, Amrita Vishwa Vidyapeetham, Health Science Campus, Cochin 682 026, India
}

\begin{abstract}
Aqueous solutions of polyvinyl alcohol (PVA) were electrospun and its characteristics were studied as a function of applied potential, tip-target distance and solution flow rate. Solutions of PVA and chitosan were homogeneously mixed and electrospun to result in blend nanofibres and their properties were investigated. Conditions were revealed under which multiscale bi-modal fibres could be electrospun in a single step, producing structures that have potential applications in tissue engineering. Electrospun fibres having a bimodal size distribution of poly(caprolactone) (PCL) were also fabricated using a modified electrospinning setup. Nanofibrous microporous PVA scaffolds were fabricated using a cryogenic grinding method with subsequent compaction. Such multiscale porous structures would offer ideal matrices for tissue engineering applications.
\end{abstract}

Keywords. Electrospinning; nanofibres; multiscale fibres; tissue engineering; scaffolds.

\section{Introduction}

The emerging field of tissue engineering uses tissuespecific cells in a three-dimensional organization, provided by a scaffolding material to simulate the functionality of any diseased or damaged organ (Mikos and Temenoff 2000). It is generally agreed that a highly porous structure with interconnected pores and a large surface area is conducive to tissue in-growth provided the appropriate adhesive and growth factors are present. The structure and size scale of porosity are also critical. Pores have to be large enough to allow access to cells (typically of the order of $10-50 \mu \mathrm{m})$, yet the pore structure must also contain pores in the nanometer regime $(10-100 \mathrm{~nm})$. The latter requirement, though not entirely well understood, appears to result from cell membrane interactions with the material and provides the basis for cell adhesion and multiplication (Divyarani et al 2007).

Such a multiscale structural functionality, which we demonstrate in the following, can be readily achieved in a one-step electrospinning process. In addition, electrospinning can also provide unique chemical functionality through spinning of blends that can modulate biodegradation and cell-material interactions (Huang et al 2003). Apart from structural and chemical functionality, biochemical and mechanical functionality is also critical in tissue-engineered structures. The scaffold must necessarily possess adequate mechanical properties depending on the tissue in question. These can be elasticity, shear and tensile strength and toughness. Electrospinning has unique advantages in providing mechanical functionality

\footnotetext{
*Author for correspondence (shantinair@aims.amrita.edu)
}

and for the production of nanocomposite nanofibres unlike any other processes (Liao et al 2006).

At present, electrospinning technique has been used as an efficient processing method to manufacture nanoscale fibrous structures for a number of applications (Huang et al 2003; Liao et al 2006). In the pharmaceutical and medical fields, for example, this technique can be used to make wound dressings (Khil et al 2003), drug delivery materials (Zeng et al 2003) and tissue-engineering scaffolds (Jin et al 2002). For tissue scaffold applications, the morphology of the resulting scaffold should closely resemble that of the extracellular matrix (ECM) of native tissues, which has a nanofibrous structure. These native ECMs act as a scaffolding to bring cells together in a tissue, to control the tissue structure and to regulate the cell phenotype (Alberts et al 1994). Recently, it has been found that the nanofibrous structure will improve the in vitro regeneration of tissues including bone (Murugan et al 2006), cartilage (Wang et al 2006), cardiovascular tissue (Xua et al 2004) and nerve and bladder, because evidence suggests that human cells can attach and organize well around fibres with diameters smaller than those of the cells (Laurencin et al 1999). In this context, electrospinning is especially advantageous because the nanofibrous scaffolds prepared from electrospinning are capable of mimicking the native extracellular matrix.

Fibre diameter is a parameter that can affect a variety of scaffold properties such as porosity, pore size and surface area. These properties are important in determining the functionality of scaffolds in tissue engineering applications. The pore size and porosity are critical features of a scaffold that affect cell attachment, proliferation, migration, and/or differentiation (Karageorgiou and Kaplan 2005). Surface topography and structural size-scale are 
additional parameters that have been shown to affect the orientation and biological function of cells (Flemming et al 1999). A scaffold possessing two or more pore size distributions could facilitate the culture of several cell types to produce multiple interfaces on a single scaffold. Additionally, a scaffold consisting of a gradient in fibre diameter (and thus pore size) has been suggested as a useful model for zonal cartilage tissue engineering (Pham et al 2006).

Both natural and synthetic materials have been investigated for use as tissue engineering scaffolds for the past few years (Hutmacher et al 2000). However, biodegradable synthetic polymers offer a number of advantages over conventional materials for developing such scaffolds. The key advantages include the ability to simultaneously tailor biological and mechanical properties and degradation kinetics to suit the target tissue. Synthetic polymers are also attractive because they can be fabricated into various shapes with desired pore morphologic features that facilitate tissue in-growth. A wide variety of polymers have been electrospun and several applications have been proposed in recent years based on the small fibre diameters and high porosities (Huang et al 2001; Yoshimoto et al 2003). These include synthetic biodegradable polymers such as poly(lactic acid) (Kim et al 2003a,b; Yang et al 2005), poly(glycolic acid) (Boland et al 2001; Li et al 2002), poly(lactic-co-glycolic acid) (Yoshimoto et al 2003; Tan et al 2005), poly(caprolactone) (Li et al 2005), or natural ones such as collagen (Matthews et al 2002), gelatin (Zhang et al 2005a, b), silk (Ohgo et al 2003; Min et al 2005), and chitosan (Min et al 2004; Sangsanoh and Supaphol 2006).

Poly(vinyl alcohol) (PVA) is a water-soluble, biocompatible and biodegradable synthetic polymer that has been studied intensely because of its good physical properties, high hydrophilicity, processability, etc (Dinga et al 2004). Electrospinning of PVA solution and its potential applications in the preparation of ultrafine separation filters, biodegradable mats, etc have been reported by many researchers (Yao et al 2003; Koski et al 2004). In recent years, much attention has been focused on the biomedical applications of PVA hydrogels including contact lenses, artificial organs and drug delivery systems (Sona et al 2005). By incorporating a second polymer component, viz. chitosan, to PVA solution, an improvement in biocompatibility of the blend system can be achieved. This can be attributed to the good biocompatibility, antibacterial properties, appropriate biodegradability, excellent physicochemical properties, and its commercial availability at relatively low cost (Huang et al 2005). As candidate materials, chitosan and PVA have been separately investigated for sutures and wound dressings. Recently, researchers have investigated electrospinning of polymer blends for biomedical applications because they provide an efficient way to fulfill new requirements for material properties (Jia et al 2006; Lin et al 2006). Chitosan/PVA blend nanofibres have not yet been explored for potential tissue engineering applications. PCL is a biocompatible, biodegradable polymer that has been successfully electrospun, which is capable of supporting a wide variety of cell types, including marrow stromal cells (MSCs) (Pham et al 2006). Due to the complexity of cell behaviour, a scaffold for tissue engineering should possess two or more pore size distributions and a gradient in the fibre diameter.

In the present work, we show structural results on electrospun PVA and chitosan/PVA blends. The effects of electric field, tip-target distance, solution flow rate and polymer concentration on the morphology of electrospun fibres were evaluated and the conditions for mutiscale structural functionality were explored. The effect of addition of a natural polymer component, viz. chitosan, to PVA solution on the structure was also investigated. Pore sizes are typically too small for cells to pass through when the electrospun fibres are all of nanoscale geometry. The nature of the structure was investigated for a multiscale electrospun mat produced using PVA and PCL. Two different techniques for producing multi-scale geometry were adopted here. We also investigated the success of a cryogenic grinding process for introducing micropores in a three-dimensional scaffold for cell access.

\section{Experimental}

\subsection{Electrospinning of PVA and chitosan/PVA blends}

Poly(vinyl alcohol) (PVA, 99\% hydrolyzed, number average molecular weight, $1,20,000 \mathrm{~g} / \mathrm{mol}$ ), chitosan (medium molecular weight, $75-85 \%$ deacetylated) and acetic acid were obtained from Aldrich. PVA solutions ( $8 \mathrm{wt} \%$ ) were prepared in distilled water at $80^{\circ} \mathrm{C}$ with constant stirring for atleast $2 \mathrm{~h}$ and subsequently cooled to ambient temperature before electrospinning. As chitosan is soluble only in acidic medium, $2 \mathrm{wt} \%$ acetic acid solution was used as its solvent. Both the polymer solutions were

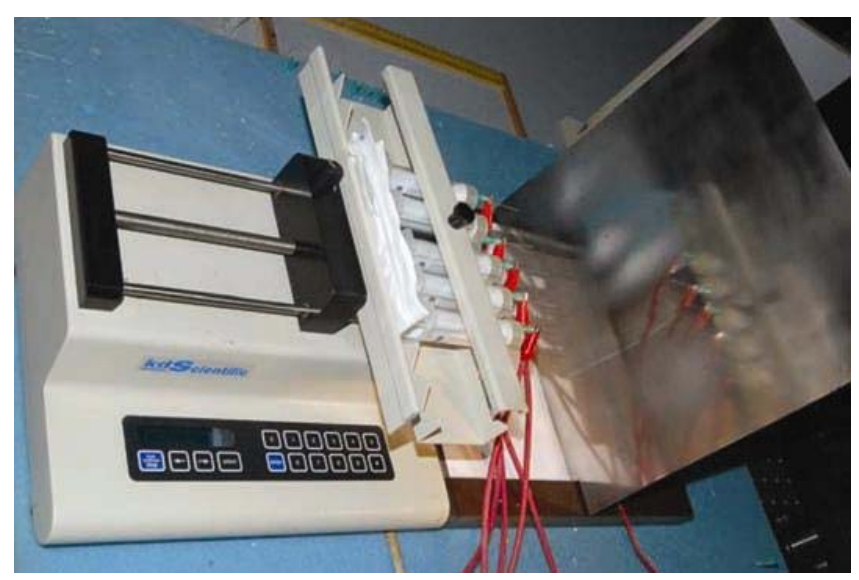

Figure 1. Multi syringe setup for electrospinning with a stationary collecting electrode. 
mixed in different proportions by intense stirring, resulting in homogeneous chitosan/PVA blends.

The electrospinning setup used in the present study is shown in figure 1. It consists of an assembly of syringes with metal needles, a syringe pump for controlling feeding rate, a high voltage d.c. power supply and a grounded flat or cylindrical stainless steel electrode. The polymer solution taken inside the syringe was delivered using a KD Scientific infusion syringe pump (Model KDS 220) at controlled flow rates. A high voltage power supply (Gamma High Voltage Inc, Model RR30P), which provided a maximum d.c. voltage of $30 \mathrm{kV}$ at a maximum of $5 \mathrm{~mA}$, was used as the source for electrospinning. The setup had provisions for stationary as well as rotating electrodes (maximum $15000 \mathrm{rpm}$ ), both made of stainless steel, on a vibration free platform for collection of the fibres deposited.

In a typical electrospinning experiment, polymer solution taken in a $20 \mathrm{ml}$ Becton Dickinson syringe was delivered to the tip of the syringe needles (21 gauge) by the syringe pump at a constant feed rate $(0.7 \mathrm{ml} / \mathrm{h})$. A positive voltage of $15 \mathrm{kV}$ was applied to the polymer solution via the stainless steel syringe needles. The electrospun polymer fibres were collected on the stationary or rotating electrode. The typical distance between the tip of the needles and the electrode was $10 \mathrm{~cm}$.

\subsection{Electrospinning of PCL fibres}

Poly(caprolactone) (PCL, MW 43,000) obtained from Polysciences Inc., USA, was used for electrospinning. Chloroform was used as the solvent for PCL (12 wt\%). The schematic of the electrospinning setup is depicted in figure 2, which is a modification of the conventional system. In this case, a stationary cylindrical electrode $(10 \mathrm{~cm}$ dia, $1 \mathrm{~cm}$ width) coaxial with the needle, was introduced beyond the needle $(0.5 \mathrm{~cm}$ away from the tip) for focusing purposes. Non-woven electrospun mats of PCL were collected on aluminum foils attached to the stationary electrode by applying a positive voltage of $20 \mathrm{kV}$.

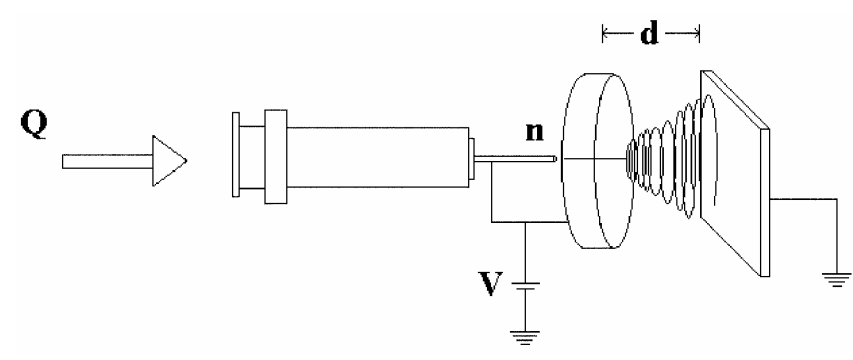

Figure 2. Schematic representation of the electrospinning setup with dual electrode. The cylindrical electrode has a diameter of $10 \mathrm{~cm}$ and a width of $1 \mathrm{~cm}$. The flow rate $(Q=$ $0.7 \mathrm{ml} / \mathrm{h})$, distance $(d=10 \mathrm{~cm})$, applied voltage $(V=20 \mathrm{kV})$ and needle gauge $(n=21)$ are shown.

\subsection{Characterization}

The viscosity of the polymer solutions was measured using a Brookfield viscometer (Model DV-II + Pro). The morphology of electrospun fibres was observed using JEOL (model JSM-6490 LA) analytical scanning electron microscope. The samples were coated with platinum using a JEOL (model JFC-1600) auto fine coater at $10 \mathrm{~mA}$ for $2 \mathrm{~min}$, before they were observed under the SEM.

\subsection{Scaffold fabrication}

Electrospun nonwoven mats of PVA were cryogenically ground to obtain the material in powdered form. This was subsequently compacted into a desired geometry using a hydraulic pellet press by applying a pressure of $\sim 50$ bar to obtain a three-dimensional scaffold.

\section{Results and discussion}

\subsection{Chitosan/PVA blend nanofibres}

The results of the viscosity of PVA and PVA/chitosan blend in both aqueous and acetic acid media are shown in table 1 . The viscosity of PVA in acetic acid was approximately the same as that of the corresponding aqueous solution of PVA. As chitosan is blended with PVA, there is a significant increase in viscosity, with both blends having viscosity values higher than that of aqueous PVA alone. Table 1 also gives the average fibre diameters determined from electron micrographs, shown in figure 3.

In the present work, electrospinning of PVA aqueous solution $(8 \mathrm{wt} \%)$ resulted in relatively large diameter fibres (420 $\pm 40 \mathrm{~nm})$ as shown in figure $3 \mathrm{a}$. For PVA dissolved in acetic acid solution (figure $3 b$ ), average diameter of the fibres reduced to $210 \pm 40 \mathrm{~nm}$ in comparison to aqueous based PVA. When chitosan was blended with PVA in different weight ratios of $1: 8$ and $2: 8$, but in the same $2 \%$ acetic acid solution, the fibre diameter was reduced when compared to that of PVA alone. The reduced diameter of the blend fibres with the addition of chitosan can be explained qualitatively as follows. Since chitosan is an ionic polyelectrolyte, during electrospinning of the blend sample, a higher charge density on the surface of ejected jet is formed. As the charges carried by the jet increase, higher elongation forces are imposed on the jet under the electric field. This is because the electric field force is proportional to the charge density on the jet, thus resulting in decreased fibre diameter with an increase in charge density. Similar observations have been made by Lin et al (2006) and Ignatova et al (2006), who investigated a series of poly(vinyl alcohol)/chitosan blend nano fibrous membranes at different weight ratios and found a decrease in the average diameter of the nano-fibres with chitosan content. 
Table 1. Measurements for PVA and PVA/chitosan blends at $15 \mathrm{kV}$

\begin{tabular}{lcccc}
\hline $\begin{array}{l}\text { Type of } \\
\text { polymer solution }\end{array}$ & $\begin{array}{c}8 \mathrm{wt} \% \text { PVA } \\
\text { in water }\end{array}$ & $\begin{array}{c}8 \mathrm{wt} \% \text { PVA in } \\
2 \mathrm{wt} \% \text { acetic acid }\end{array}$ & $\begin{array}{c}1: 8 \text { Chitosan : PVA } \\
\text { in 2 wt\% acetic acid }\end{array}$ & $\begin{array}{c}2: 8 \text { Chitosan : PVA } \\
\text { in 2 wt \% acetic acid }\end{array}$ \\
\hline $\begin{array}{l}\text { Viscosity (cP) at } 25 \cdot 8^{\circ} \mathrm{C} \\
\text { Calculated charge from } \mathrm{pH}\left(\mathrm{C} / \mathrm{L} \times 10^{-6}\right)\end{array}$ & 528 & 527 & 644 & 1028 \\
Average fibre diameter $(\mathrm{nm})$ & $420 \pm 40$ & $210 \pm 40$ & $44 \cdot 25$ & $47 \cdot 77$ \\
\hline
\end{tabular}
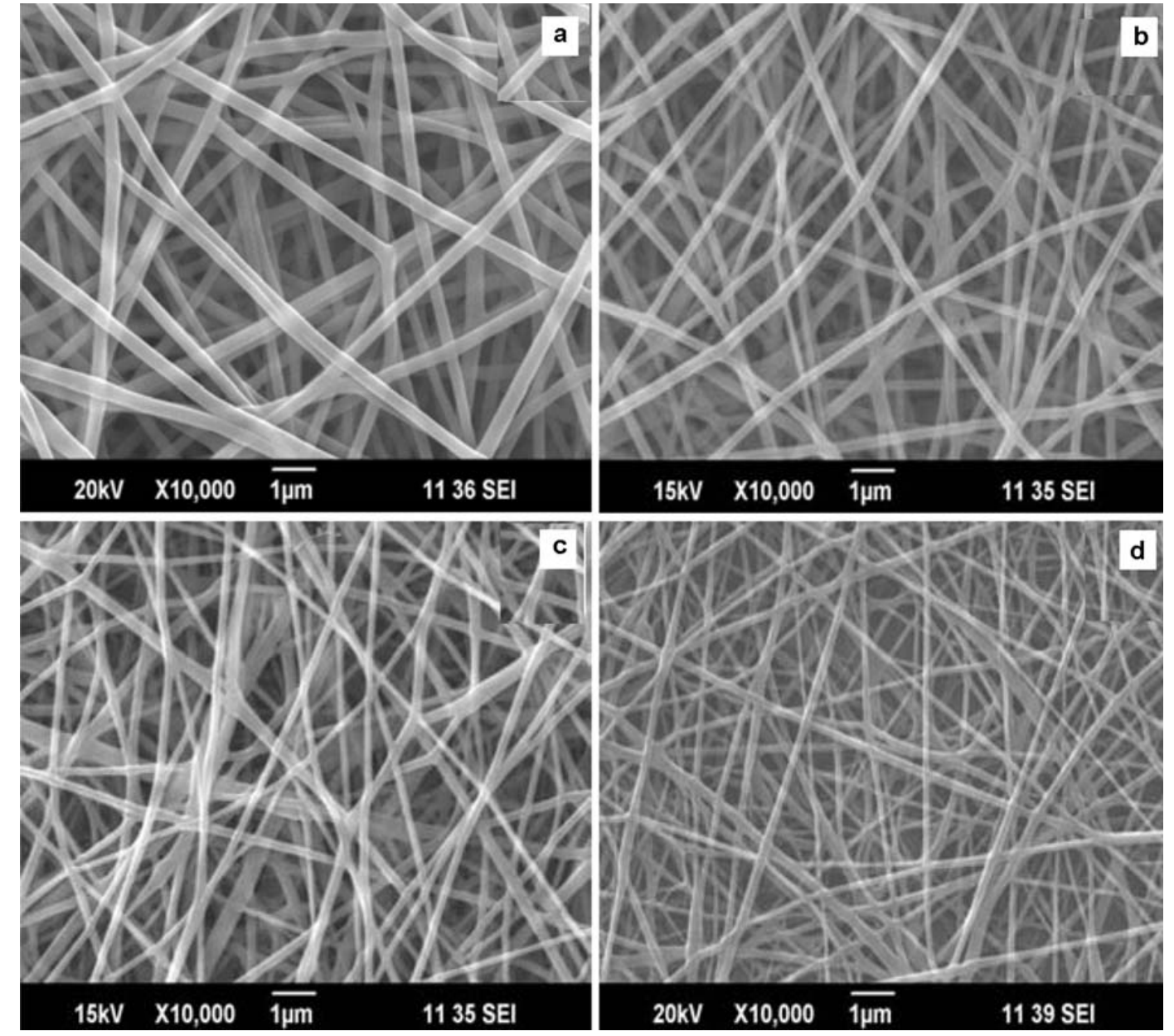

Figure 3. SEM micrographs of nanofibres produced from a. 8 wt $\%$ PVA aqueous solution, b. 8 wt $\%$. PVA in $2 \%$ acetic acid solution, $\mathbf{c}$. chitosan/PVA blend at $1: 8$ and $\mathbf{d}$. chitosan/PVA blend at $2: 8$ (by weight).

The fibre diameter, however, is not only dependent on the charge, but also on the viscosity of the solution. Typically, when the viscosity is increased, the diameter increases as well, contrary to what we observed. To explain the decrease in diameter with increasing viscosity, we assert that the charge dominated over viscosity. To demonstrate this quantitatively we present the following simple model for the drawing process during electrospinning. The extension rate during drawing can be expressed in terms of the force, $F$, and viscosity, $\eta$, based on a creep equation as follows

$(\mathrm{d} L / \mathrm{d} t) / L=F / \eta A$.

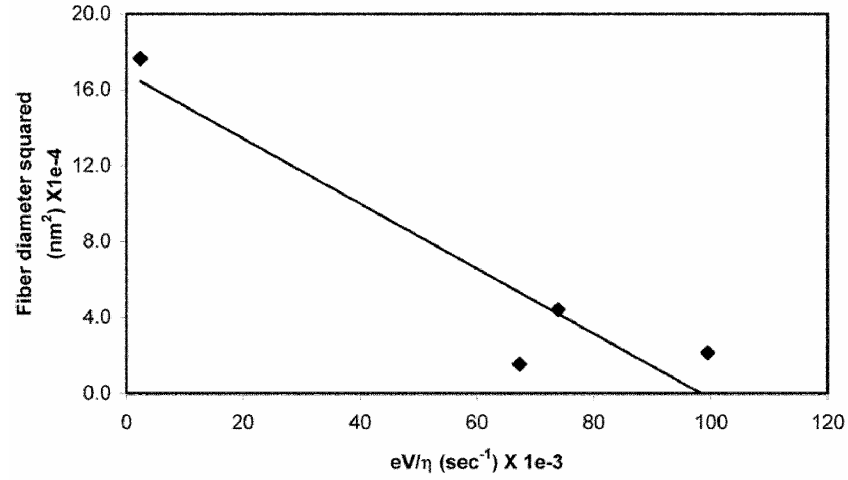

Figure 4. Relationship of fibre diameter squared $v s \mathrm{eV} / \eta$ for a fixed voltage of $15 \mathrm{kV}$. 

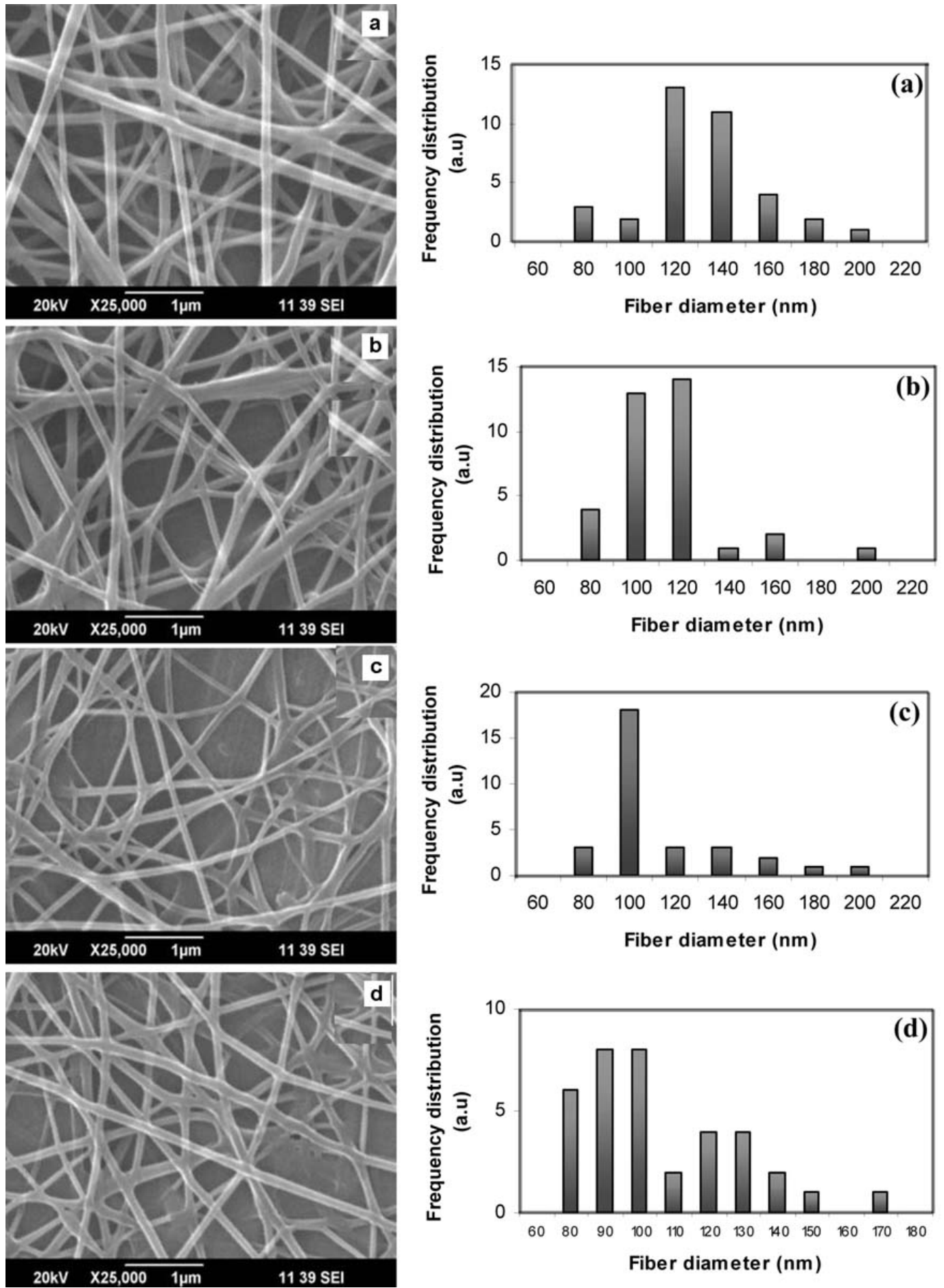

Figure 5. SEM images of $2: 8$ chitosan/PVA blend samples showing the variation of fibre diameter with applied voltages of (a) $10 \mathrm{kV}$, (b) $15 \mathrm{kV}$, (c) $20 \mathrm{kV}$, and (d) $25 \mathrm{kV}$ at a tip-target distance of $4 \mathrm{~cm}$.

Since the electric field force is proportional to the charge and is equal to $\mathrm{eV} / \mathrm{h}$, where $V$ is the voltage, $h$ the tip-target distance and $e$ the charge. Also for constant volume deformation, $A d L=-L d A$, so that (1) can be written as

$$
d A=d\left(d^{2}\right) \propto \frac{e V}{\eta} d t \quad \text { or } \quad d_{0}^{2}-d^{2}=\alpha \frac{e V}{\eta},
$$

where $\alpha$ is a constant and $d_{0}$ a reference diameter (constant). A plot of (2) is shown in figure 4 based on the results in table 1 for constant voltage, $V$, which shows that there is reasonable quantitative agreement with the qualitative hypothesis that increase in charge in this case had a stronger effect than increase in viscosity. Figure 4 shows that $e V / \eta$, in fact, increased and hence the fibre diameter decreased. 


\subsection{Effect of voltage on fibre diameter distribution of PVA/chitosan blends}

The effect of applied voltage on the diameter of electrospun fibres was noted for both PVA and chitosan/PVA systems. A series of experiments were carried out at fixed tip to target distance when the applied voltage was varied from 5 to $25 \mathrm{kV}$. The dependence of fibre diameter distribution for chitosan/PVA blend as a function of applied voltage is shown in figure 5 , with their corresponding SEM images. The average fibre diameter of electrospun fibres was measured using the software provided with JEOL SEM. As is evident from the figure, the fibre diameter decreased with increasing voltage. Increasing the electric field strength resulted in an enhancement in the electrostatic repulsive force on the fluid jet thus favouring thinner fibre formation. The variation of fibre diameter of electrospun PVA with applied potential, using the optimal concentration ( $8 \mathrm{wt} \%$ aqueous PVA) is shown graphically in figure 6, where $e$ and $\eta$ are constants and only voltage varied. The results are consistent with the simple model presented.

\subsection{Effect of varying tip-target distance and flow rate}

Our experiments reveal that tip-target distance did not critically influence the electrospun fibre morphology of chitosan/PVA fibres. The SEM images, shown in figure 7 , could not distinguish differences in fibre diameter for electrospinning carried out at tip-target distances in the range $4-8 \mathrm{~cm}$. For the tip-target distance variation considered in the present work, the average fibre diameter was found to be $100 \pm 20 \mathrm{~nm}$. Due to the high conductivity of the polymer solution, the solution jets solidified immediately after they got ejected from the needle tip, hence obstructing the formation of uniform fibres at tiptarget distances $>8 \mathrm{~cm}$.

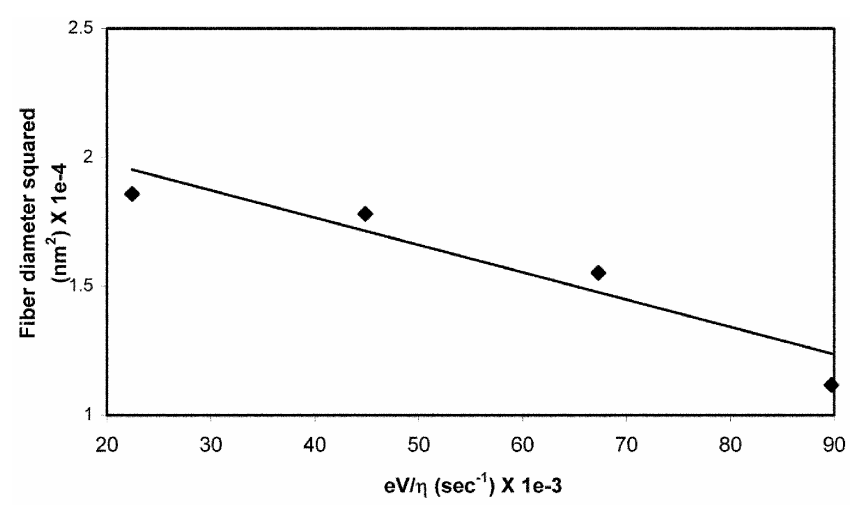

Figure 6. Variation of fibre diameter with applied voltage for electrospun chitosan/PVA $(2: 8 \mathrm{wt} \%)$ fibres at a tip-target distance of $10 \mathrm{~cm}$

\subsection{PVA multi-scale fibres}

Remarkable variations in the diameter of electrospun PVA fibres were observed when the flow rate was altered from the earlier constant rate of $0.7 \mathrm{ml} / \mathrm{h}$. We were successful in getting multi-scale fibre geometry for PVA as well as the blends, which consisted of micro-nano hybrid fibres. Such kind of a multi-scale geometry can offer a better tissue-engineered matrix for scaffold preparation. A typical SEM image of this multi-scale fibre geometry for PVA is shown in figure 8 with the corresponding fibre diameter distribution in the range extending from $200 \mathrm{~nm}$ to $1.4 \mu \mathrm{m}$. An earlier report on sequential fibre spinning resulting in layered nano and micro scale fibre structure has been found to aid better cell adhesion and spreading (Pham et al 2006). However, the present method is able to provide controlled multiscale structure in a single step process by varying the flow rate from $0.1 \mathrm{ml} / \mathrm{h}$ to $1.3 \mathrm{ml} / \mathrm{h}$ and the voltage from $10 \mathrm{kV}$ to $25 \mathrm{kV}$. It is well understood that fibre diameter increases with feed rate. Due to the greater volume of solution drawn from the needle tip, the jet takes a longer time to dry, resulting in the fibres to fuse together forming multi-scale fibres.

\subsection{Multiscale fibres of PCL}

A unique bimodal multiscale fibre geometry has been obtained by electrospinning PCL using a dual electrode setup. In the present work, PCL containing needle is placed at the centre of the cylindrical electrode in such a way that the macroscopic radial electric field generated by the cylindrical electrode acts at the splaying region of the electrospinning jet. In the electrospinning process, with increasing electric potential, the charged pendent drop of the polymer solution formed at the tip of the capillary deformed into a cone known as 'Taylor cone' (Reneker et al 2000; Yarin et al 2005). At critical field when the force due to the electric field overcomes the surface tension forces holding the droplets, the solution starts flowing into the form of a charged jet. This jet becomes branched and generally the direction of the branched jet is perpendicular to the axis of the primary jet. Soon after this region, the electrospun jet splits into thousands of components, resulting in the splaying region (Yarin et al 2001). This is the region where the bending instability and the chaotic transit of the jet initiate. SEM pictures of PCL fibres formed with and without cylindrical dual electrode are shown in figures $9 \mathrm{a}$ and $\mathrm{b}$, with their corresponding fibre diameter distribution on the right.

In the present study, an electric field is applied at the region where the bending instability gets started, or at the splaying region. Since the electric field gradient exerted on different regions of the jet varies, the electrostatic force acting on the jet is different. When a conducting jet is formed, majority of the carriers resides on the surface 


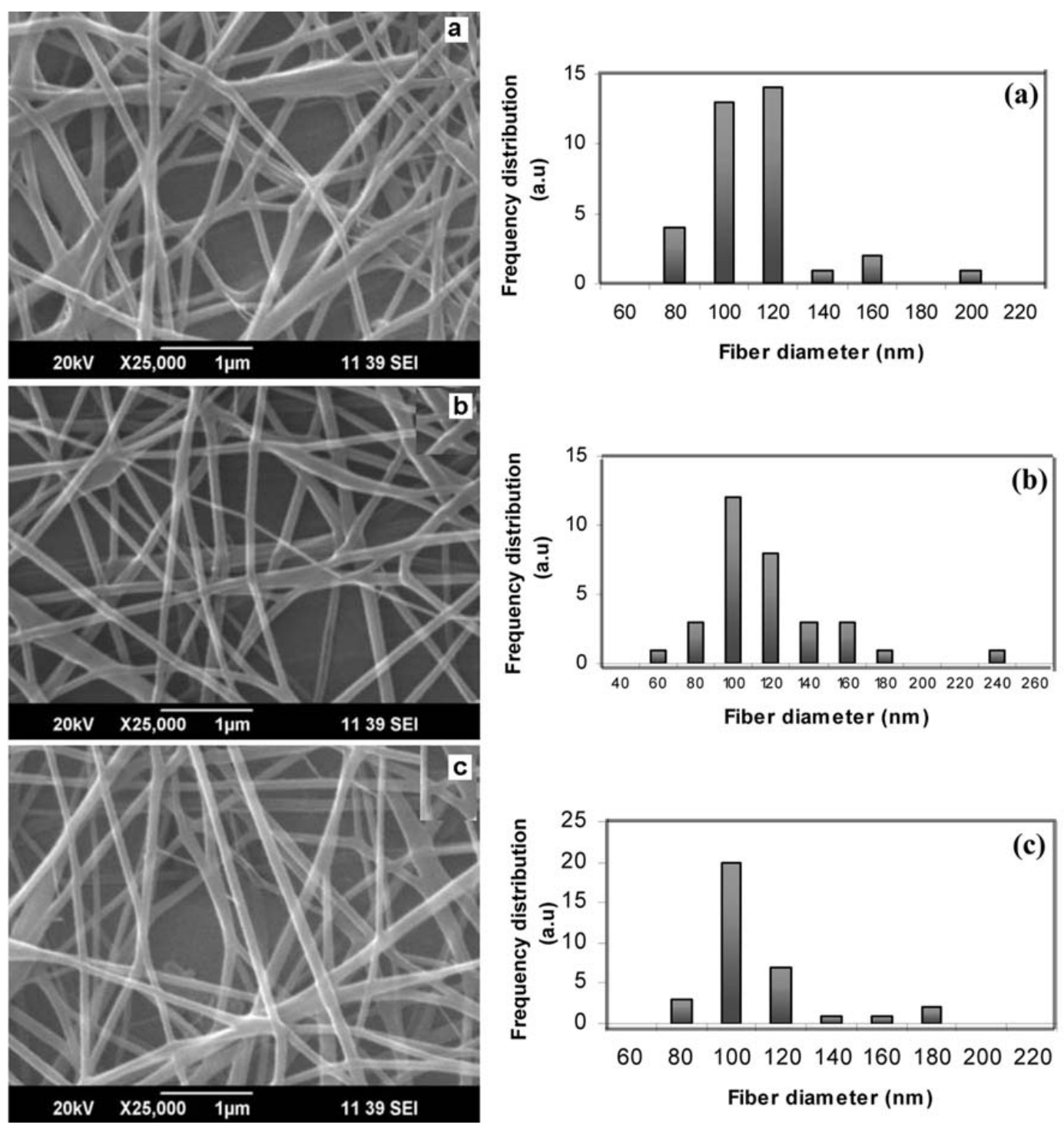

Figure 7. SEM images of chitosan/PVA $(2: 8)$ blend samples showing the variation of fibre diameter distribution with tip-target distance at (a) 4 , (b) 6 and (c) $8 \mathrm{~cm}$ at $15 \mathrm{kV}$.
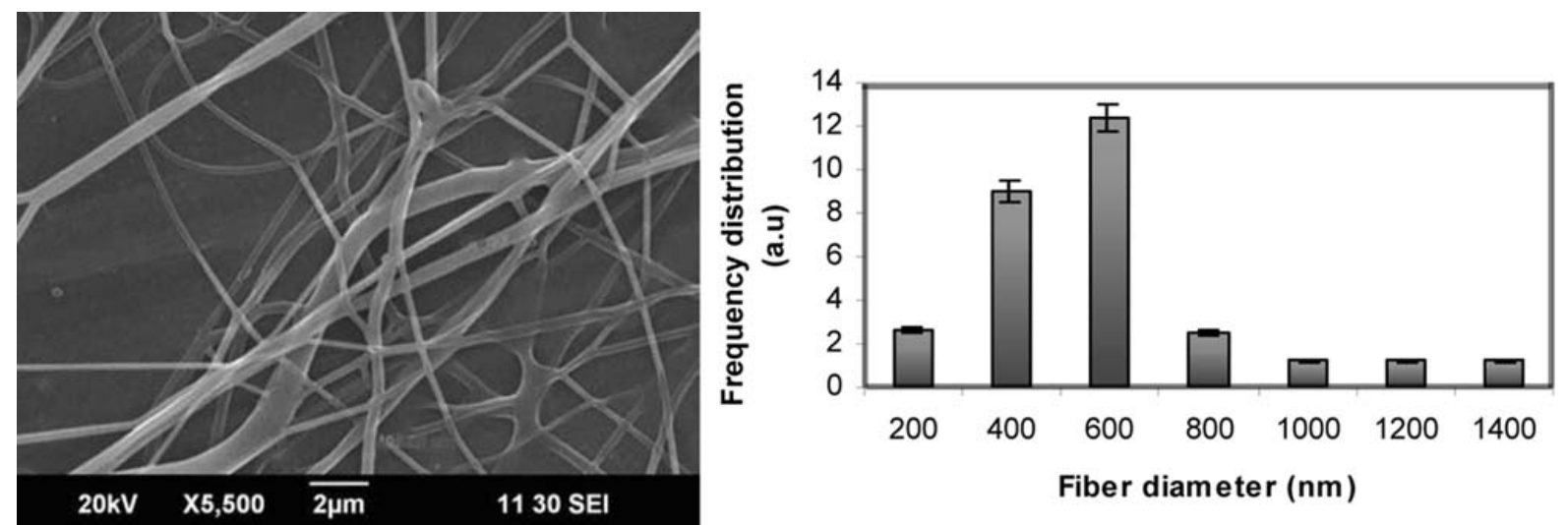

Figure 8. SEM image of multi-scale PVA fibres and its corresponding fibre diameter distribution. 

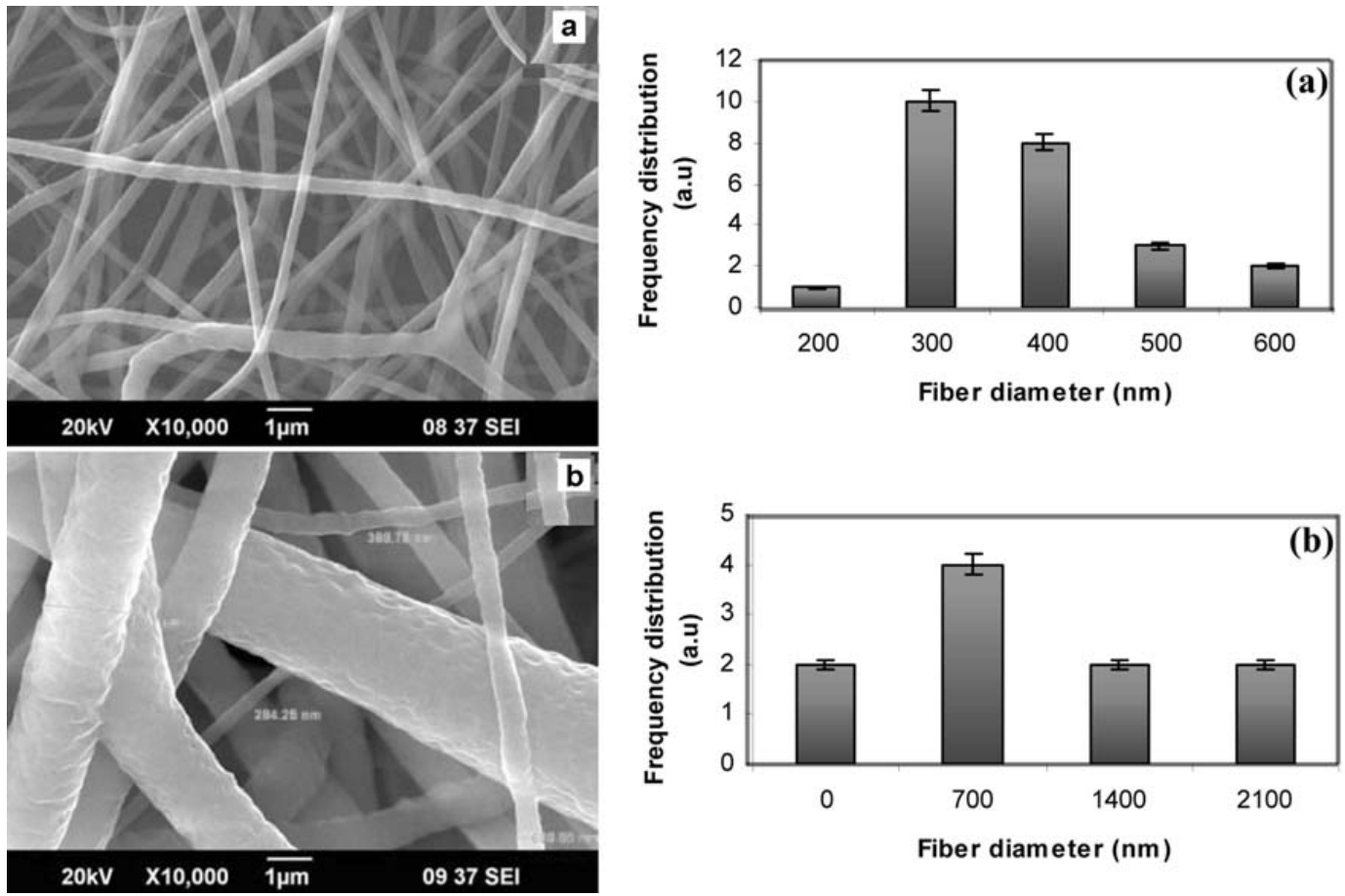

Figure 9. a. SEM image of PCL nanofibres obtained by electrospinning using stationary target and $\mathbf{b}$ multiscale fibres of PCL using cylindrical electrode. (PCL, $12 \mathrm{wt} \%$; viscosity $=181 \mathrm{cps}$; electrode distance, $10 \mathrm{~cm}$ from the electrode)
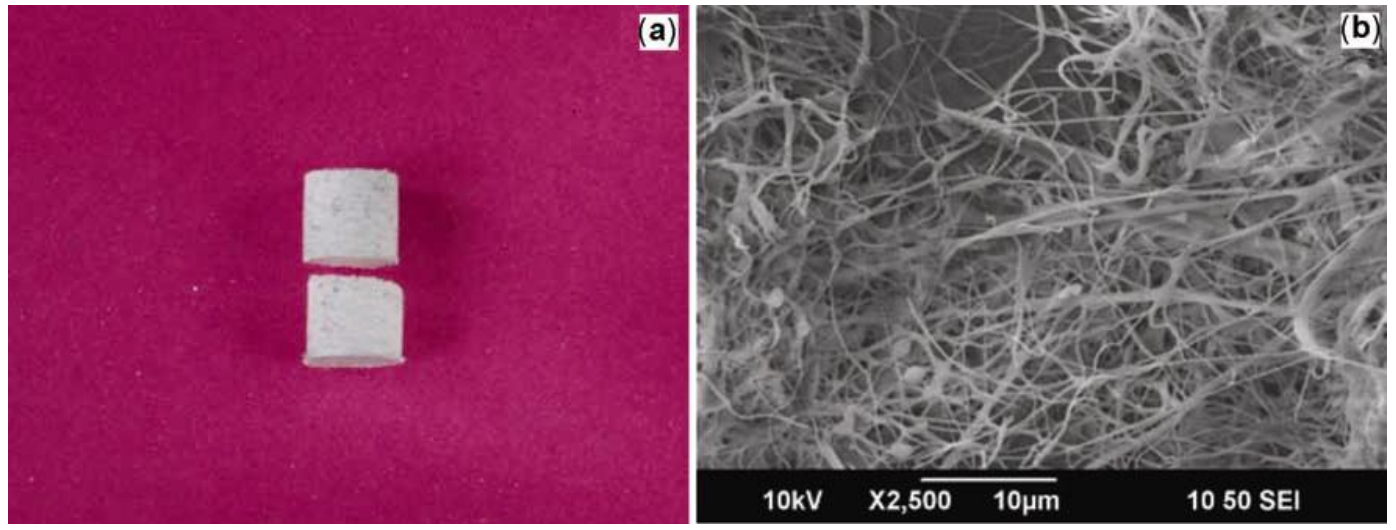

Figure 10. (a) Digital photograph and (b) cross-sectional SEM image of electrospun PVA nanofibrous scaffold.

of jet. When splaying starts, splitting of the charged jet at certain regions of the fluid jet will be suppressed by the external electric field. By this process, we have been successful in obtaining a range of diameters from $200 \mathrm{~nm}-$ $2.5 \mu \mathrm{m}$, whereas spinning with stationary electrode setup resulted in 200-500 nm fibres. From the SEM pictures it is evident that the fibre mat contains nano and micro fibres, which will provide an ideal material for the fabrication of scaffolds.

\subsection{Three-dimensional scaffold preparation using electrospun mats}

The digital photograph of our nanofibrous microporous 3$\mathrm{D}$ scaffold is shown in figure $10 \mathrm{a}$, with the cross-sectional SEM image of the same sample in figure 10b. The SEM image clearly depicts varied porosities in the sample of the order of 10-20 microns, which would offer an ideal situation for cell attachment and proliferation. Further 
studies are underway to evaluate the feasibility of this product for tissue engineering applications.

\section{Conclusions}

Electrospinning was used to fabricate nanofibres of PVA, chitosan/PVA blends and PCL. The effect of processing parameters such as voltage, tip-target distance and flow rate on fibre diameter and its morphology has been evaluated. The results are consistent with a simple extensional creep model for electrospinning. A new approach has been presented for obtaining multiscale fibres and also for processing of microporous, but nanoscale scaffolds that have potential for tissue engineering purposes.

\section{Acknowledgement}

The authors are thankful to the Department of Science and Technology, Government of India, for financial support through the Nanoscience and Nanotechnology (NS \& NT) initiative headed by Professor C N R Rao.

\section{References}

Alberts B, Bray D, Lewis J, Raff M, Roberts K and Watson J D 1994 Molecular biology of the cell (Garland: Garland Publishing)

Boland E D, Wnek GE, Simpson D G, Pawlowski K J and Bowlin G L 2001 J. Macromol. Sci. 381231

Dinga B, Kimuraa E, Satoa T, Fujitaa S and Shiratori S 2004 Polymer 451895

Divyarani V V, Anitha V C, Manju T, Seema Nair P, Deepthy Menon and Shanti Nair 2007 (unpublished)

Flemming R G, Murphy C J, Abrams G A, Goodman S L and Nealey P F 1999 Biomaterials 20573

Huang L, Nagapaudi K, Apkarian R P and Chaikof E L $2001 \mathrm{~J}$. Biomater. Sci. Polym. Ed. 12979

Huang Y, Onyeri S, Siewe M, Moshfeghian A and Madihally S V 2005 Biomaterials 267616

Huang Z M, Zhang Y Z, Kotaki M and Ramakrishna S 2003 Compos. Sci. Technol. 632223

Hutmacher D W 2000 Biomaterials 212529

Ignatova M, Starbova K, Markova N, Manolovaa N and Rashkova I 2006 Carbohydr. Res. 3412098

Jia Y T, Gong J, Gu X H, Kim H Y, Dong J and Shen X Y 2006 Carbohydr. Res. 341374

Jin H J, Fridrikh S V, Rutledge G C and Kaplan D I 2002 Biomacromolecules 31233

Karageorgiou V and Kaplan D 2005 Biomaterials 265474
Khil M S, Cha D I, Kim H Y, Kim I S and Bhattarai N 2003 J. Biomed. Mater. Res. B67 675

Kim S H, Nam Y S, Lee T S and Park W H 2003a Polym. J. 35 185

Kim K et al 2003b Biomaterials 244977

Koski A, Yim K and Shivkumar S 2004 Mater. Lett. 58493

Laurencin C T, Ambrosio A M A, Borden M D and Cooper Jr J A 1999 Rev. Biomed. Eng. 119

Li W J, Laurencin C T, Caterson E J, Tuan R S and Ko F K J 2002 Biomed. Mater. Res. 60613

Li W J, Tuli R, Okafor C, Derfoul A, Danielson K G, Hall D J and Tuan R S 2005 Biomaterials 26599

Lin T, Fang J, Wang H, Cheng T and Wang X 2006 Nanotechnology 173718

Liao S, Li B, Ma Z, Wei H, Chan C and Ramakrishna S 2006 Biomed. Mater. 1 R45

Matthews J A, Wnek G E, Simpson D G and Bowlin G L 2002 Biomacromolecules 3232

Mikos A G and Temenoff J S 2000 Electron. J. Biotechnol. 3 114

Min B M, Lee G, Kim S H, Nam Y S, Lee T S and Park W H 2004 Biomaterials 251289

Murugan R, Ramakrishna S and Panduranga Rao K 2006 Mater. Letts 602844

Ohgo K, Zhao C, Kobayashi M and Asakura T 2003 Polymer 44841

Pham Q P, Sharma U and Mikos A G 2006 Biomacromolecules 72796

Reneker D H, Yarin A L, Fong H and Koombhongse S $2000 \mathrm{~J}$. Appl. Phys. 874531

Sangsanoh P and Supaphol P 2006 Biomacromolecules 72710

Sona W K, Youkb J H, Leec T S and Park W H 2005 Mater. Letts 591571

Tan E P S, Ng S Y and Lim C T 2005 Biomaterials 261453

Wang Y, Blasioli D J, Kim Hyeon-Joo, Kim Hyun Suk and Kaplan D L 2006 Biomaterials 274434

Xua C Y, Inaic R, Kotaki M and Ramakrishna S 2004 Biomaterials 25877

Yang F, Murugan R, Wang S and Ramakrishna S 2005 Biomaterials 262603

Yao L, Haas T W, Elie A G, Bowlin Gary L, Simpson D G and Wnek G E 2003 Chem. Mater. 151860

Yarin A L, Koombhongse S and Reneker D H 2001 J. Appl. Phys. 904836

Yarin A L, Kataphinan W and Reneker D H 2005 J. Appl. Phys. 98064501

Yoshimoto H, Shin Y M, Terai H and Vacanti J P 2003 Biomaterials 242077

Zeng J, Xu X, Chen X, Liang Q X, Bian Q, Yang L and Jing X 2003 J. Control. Release 92227

Zhang Y Z, Ouyang H W, Lim C T, Ramakrishna S and Huang Z M J 2005a Biomed. Mater. Res. Part B B72 156

Zhang C, Yuan X, Wu L, Han Y and Sheng J 2005b Eur. Polym. J. 41423 